\title{
Hyaline Membrane Disease
}

\author{
II: Lung Lecithin
}

\author{
K. BOUGHTON, * GILLIAN GANDY, and DOUGLAS GAIRDNER \\ From the Cambridge Maternity Hospital
}

Boughton, K., Gandy, G., and Gairdner, D. (1970). Archives of Disease in Childhood, 45, 311. Hyaline membrane disease. II: Lung lecithin. The lecithin content of lung, together with its surface tension properties, were determined in 34 stillbirths, and 61 neonatal deaths. Lecithin content ranged widely from $1 \cdot 5$ to $18 \cdot 6 \%$ of dry lung tissue.

In 24 cases the 'palmitic-lecithin' was also measured; it formed $44-79 \%$ of the total lecithins. Since the two were related linearly, changes in palmitic-lecithin could be adequately studied by measuring total lecithins.

Lecithin content was negatively correlated with minimum surface tension of lung extract in both fresh stillbirths and neonatal deaths. Cases with hyaline membranes had lung lecithin in the lower range ( $<8 \%$ dry tissue). Lung lecithin content may be a measure of surfactant reserve.

After 29 weeks' gestation, fresh stillbirths and neonatal deaths, other than those with hyaline membranes, had normal lung surfactant. The exception was a small group of infants having immature lungs lacking surfactant, and who survived less than $2 \frac{1}{2}$ hours; some of these, it is surmised, would have developed hyaline membranes had they survived longer. This was consistent with the fact that well-formed hyaline membranes were only found in infants that had survived for at least 3 hours.

Surfactant deficiency probably develops only after birth (except in very immature infants), and as a consequence of an initial rapid consumption of surfactant to form a lining layer covering the alveolar surface, when a gas-liquid interface is created by aeration of lung. Surfactant deficiency, by promoting interstitial pulmonary oedema, is thought to be the immediate cause of hyaline membrane disease.

A scheme for the pathogenesis of hyaline membrane disease is set out. It provides a possible mechanism for the different ways in which surfactant deficiency may arise in immature and mature infants.

Cases where hyaline membranes occur with normal surfactant fall into three groups: (1) Cases with hyaline membrane disease that have survived several days, the lungs being in the stage of repair. (2) Cases with massive lung haemorrhage, with severe anaemia from haemolytic disease, or with heart failure; extravasation of oedema fluid or blood may be the common factor in this group. (3) Infants of diabetic mothers.

In the preceding paper (Gandy, Jacobson, and Gairdner, 1970) histological studies of human lung have shown that the presence of osmiophilic granules correlates well with the presence of surfactant. Both are usually found in fetuses and liveborn infants of more than 29 weeks' gestation,

Received 27 November 1969.

^Present address: 4 Kingsbury Place, Pietermaritzburg, Natal, S. Africa. but are not found in infants dying from hyaline membrane disease (HMD) in the first few days of life. However, the role of surfactant deficiency in HMD remains debatable; though such deficiency is undoubtedly responsible for the progressive atelectasis, it remains to be shown that it could also account for the epithelial cell necrosis which we have found to be an early change in the development of HMD. This possibility is further examined in the present paper. 
There is a large amount of evidence that dipalmitoyl lecithin is an important constituent of lung surfactant (Klaus, Clements, and Havel, 1961; Brumley et al., 1967a). For this reason a study was carried out analysing lung tissue for its lecithin content, and the results are reported here. Combining the results from both papers leads us then to put forward a scheme for the pathogenesis of HMD.

\section{Material and Methods}

Post-mortem material was available from a total of 95 perinatal deaths, made up as follows:

(1) 15 fresh stillbirths; fetal death, as judged by cessation of heart-beat, had taken place less than 10 hours before delivery.

(2) 19 non-fresh stillbirths: fetal death had taken place more than 10 hours before delivery, and most fetuses were macerated.

(3) 60 liveborn infants dying within 8 days of birth, and 1 dying aged 5 weeks.

Necropsy was usually performed within 4 days after a stillbirth delivery or a neonatal death, the body being meanwhile refrigerated. Samples of lung were studied in three ways.

(i) Minimum surface tension $\left(\mathrm{T}_{\min }\right.$.) of a saline extract of lung homogenate was measured on a Wilhelmy balance as described previously (Gandy et al., 1968).

(ii) Histological sections stained with haematoxylineosin were examined. Hyaline membranes (HM) were graded 1 to $3+$

(iii) Pieces of lung were deep frozen at $-20^{\circ} \mathrm{C}$. for lipid analysis; after storage, weighed portions (1-2 g.) were freeze-dried and then reweighed. Lipids were extracted in chloroform-methanol $(2: 1 \mathrm{v} / \mathrm{v})$, and $50 \mu$ l. aliquots of the lipid extracts were analysed in triplicate for phosphorus by the method of Bartlett (1951), modified by Usher (1963); total lipid phosphorus content was calculated on the basis of dry weight using a factor of 25. Aliquots of chloroform-methanol extract were analysed in duplicate by thin-layer chromatography for phospholipid composition; glass slides were prepared with a slurry of silica $G$ in chloroform, the chromatograms being developed in chloroformmethanol-water $(10: 5: 1 \mathrm{v} / \mathrm{v})$. The plates were sprayed with rhodamine-fluorescein (Jones et al., 1966) and examined under ultraviolet light; identification of the lecithin band was aided by a marker spot of dipalmitoyl lecithin. The bands corresponding to (a) the lecithins, and (b) the remaining phospholipids, were scraped into separate tubes for phosphorus determinations, the lecithin fraction was then expressed as a percentage of total phospholipids.

In 24 of the 95 cases the analysis was carried a step further, and the proportions of fatty acids in the lecithin fraction were determined by gas-liquid chromatography; fatty acids were hydrolysed and then methylated with diazomethane (Schlenk and Gellerman, 1960), excess diazomethane and solvent were removed by a gentle stream of nitrogen at $40^{\circ} \mathrm{C}$. The dried residue was dissolved in $0.5 \mathrm{ml}$. hexane, and $1 \mu \mathrm{l}$. aliquots were injected into the chromatographic column (Perkin Elmer model F.11); known amounts of standard fatty acid methyl esters injected under identical conditions $\overrightarrow{\vec{F}}$ enabled individual fatty acids to be identified and their $-\frac{7}{0}$ relative amounts estimated by measuring the peak areas.

In 7 of the 24: cases, the lecithin fraction was separated $\frac{}{\bar{N}}$. into acetone-precipitated and acetone-soluble fractions $\frac{\text { Th }}{\vec{D}}$ as described by Gluck et al. (1967); each of the two $\stackrel{\mathbb{Q}}{\Omega}$ fractions was then examined by gas-liquid chromato- 0 graphy as already described, and the proportions of the different fatty acids measured.

\section{Results}

Phospholipids in lung tissue. In the $95 \%$ cases, total phospholipids formed from 3.0 to $\mathrm{G}$ $23.5 \mathrm{~g}$. per $100 \mathrm{~g}$. dry lung tissue.

Lecithins in lung tissue. Expressed as g. $\dot{\vec{\omega}}$ lecithins per $100 \mathrm{~g}$. phospholipid, the lecithin $\vec{\circ}$ fraction constituted from $34 \cdot 8$ to $83 \cdot 2 \%$ of total 은 phospholipid. Expressed as g. lecithins per $100 \mathrm{~g}$. $\overrightarrow{\mathrm{c}}$ dry lung tissue, the lecithins constituted from $1.5 \%$ to $18 \cdot 6 \%$ of dry lung tissue.

Fatty acids of lecithin. Palmitic acid accounted for the largest fraction of the fatty acids of the $\square$ lecithins, constituting from 44 to $79 \%$ of the total fatty acids. The range of values of the other fatty acids was as follows: oleic $6-37 \%$; stearic $5-20 \%$; palmitoleic from a trace to $8 \%$; myristic and linoleic $\underset{\mathbb{Q}}{\mathbb{Q}}$ present in traces only.

Dipalmitoyl lecithin (DPL) is known to form a $\frac{\vec{\circ}}{3}$ major component of lung phospholipids (Brown, 1962), the high proportion of this lipid being characteristic for the lung (Thannhauser, Benotti, and Boncoddo, 1946). DPL also has the property of forming a film, when spread on saline, with surface tension properties quite similar to those of lung extracts. For these reasons the estimation 8 of DPL in lung specimens from perinatal deaths would be desirable, but this is unfortunately $\circ$ difficult. If, however, the proportion of total fatty acids formed by palmitic, is multiplied by the lecithin content of lung tissue, a value for 'palmiticlecithin' is obtained. 'Palmitic-lecithin' includes $\sigma$ not only di-palmitoyl lecithin, but also the various $N$ mono-palmitoyl lecithins where palmitic acid స్心 occupies either the $\alpha$ - or the $\beta$-position. In Fig. 10 palmitic-lecithin is plotted against total lecithin in 24 cases; a linear relation is evident. It was therefore concluded that it would be no less appropriate $\stackrel{D}{\rightarrow}$ to express our results in terms of total lecithin, as in terms of palmitic-lecithin. The main part of this study thus concerns the total lecithin content of lung. 


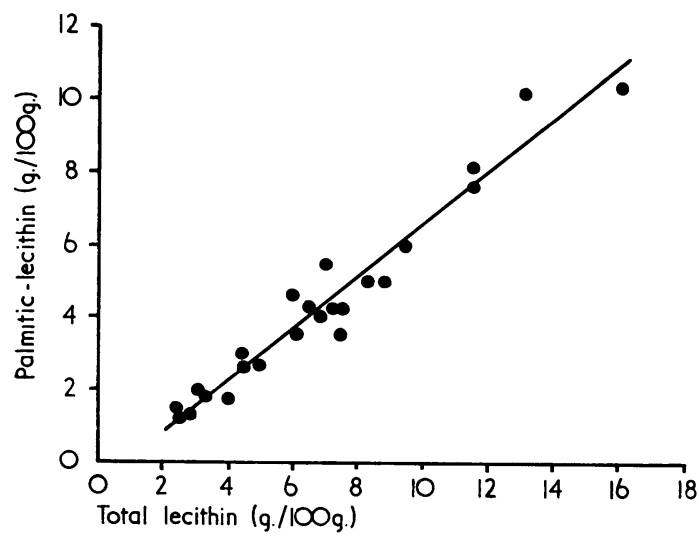

FIG. 1.-Relation of palmitic-lecithin to total lecithin in lung tissue in 24 perinatal deaths. Regression line, $y=-0.6165+0.7169 x ; \quad r=0.9741 ; p<0.001$.

Acetone-precipitated lecithin. In 7 specimens acetone-precipitated and acetone-soluble fractions were analysed separately for their fatty acid components. This group was made up of 3 livebirths without $H M, 2$ livebirths with $H M$, and 2 fresh stillbirths. The proportion of lecithins which were acetone-precipitated varied between 52 and $73 \%$ in the 7 cases.

Comparing the individual fatty acid composition of the acetone-precipitated fractions with that of the acetone-soluble fraction in each individual case, no large or consistent differences were discerned. In both fractions the pattern of fatty acids was much the same as that described above for the total lecithin, with palmitic acid forming the largest component. Therefore, we did not pursue further the fractionation of lecithins according to acetone solubility. ${ }^{\star}$

Relation of lung lecithin to minimum surface tension. Results are given separately for four groups of cases: (a) livebirths without HM, 26 cases; (b) fresh stillbirths, 15 cases; (c) nonfresh stillbirths, 19 cases; (d) livebirths with HM, 35 cases.

(a) Livebirths without hyaline membrane (Fig. 2). In this and subsequent diagrams a horizontal broken line is shown corresponding to a $T_{\min }$. value of 15 dynes/cm.; in keeping with our own studies (Gandy et al., 1968) and those of others, all

^Dr. L. Gluck (personal communication) finds that in both acetone fractions the $\alpha$-carbon fatty acids are predominantly palmitic, but that they differ in respect of the $\beta$-carbon fatty acids. These are predominantly saturated fatty acids in the acetone-precipitated fraction, whereas there are considerable amounts of unsaturated fatty acids in the acetone-soluble fraction.

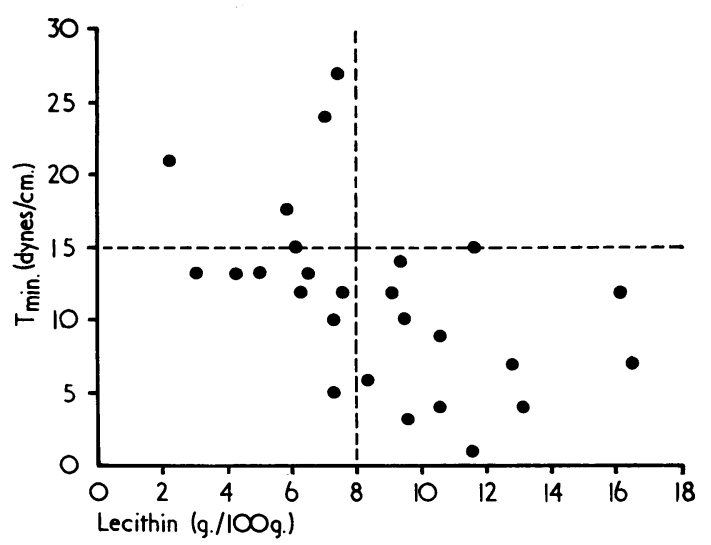

FIG. 2.-Lung lecithin related to minimum surface tension in 26 neonatal deaths without hyaline membrane. $r=$ $-0.4875 ; 0.001<p<0.01$. Normal surface tension $\leqslant 15$ dynes $/ \mathrm{cm}$. Cases are divided into a low-rang? $(<8)$ and high range $(>8)$ of lecithin values.

values of 15 dynes $/ \mathrm{cm}$. or less have been accepted as indicating normal surface tension.

There is a highly significant negative correlation between $T_{\min }$. and the lecithin content of lung. Of the 26 cases, only 4 had abnormal surface tension $\left(T_{\min }>15\right.$ dynes $/ \mathrm{cm}$.), and all fell into the lower range of lung lecithin, with values below $8 \mathrm{~g} . / 100 \mathrm{~g}$. All 4 had died within $2 \frac{1}{2}$ hours of birth, whereas this was so in only 2 of the other 22 cases of this group with normal surfactant (see Discussion).

Among the 22 cases with normal surface tension, the most immature infant being of 24 weeks' gestation, there was a wide range of lecithin values, from 3.2 to 16.6 g. $/ 100$ g., with roughly equal numbers having lecithin less than or greater than $8 \mathrm{~g} . / 100 \mathrm{~g}$.

(b) Fresh stillbirths (Fig. 3). In this group of

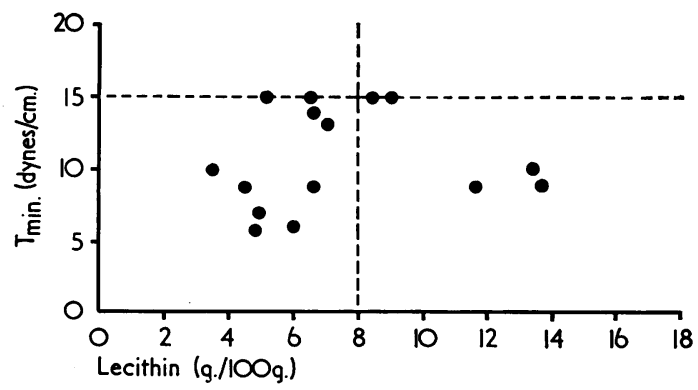

FIG. 3.-Lung lecithin related to minimum surface tension in 15 fresh stillbirths of 30 weeks' or more gestation. All have normal surface tension. 
15 cases, the shortest gestation period was 30 weeks; all had normal lung surface tension. Their lecithin values ranged from 3.4 to $13.6 \mathrm{~g} . / 100 \mathrm{~g}$., the larger number $(11 / 15)$ being less than $8 \mathrm{~g} . / 100 \mathrm{~g}$.

(c) Non-fresh stillbirths (Fig. 4). This group contained many macerated specimens, and the results differed considerably from those in fresh stillbirths. The majority (13/19) lacked surfactant $\left(T_{\min } .>15\right.$ dynes $\left./ \mathrm{cm}.\right)$ and all except 2 cases fell into the lower range of lecithin values, well below $8 \mathrm{~g} . / 100 \mathrm{~g}$. The two stillbirth cases with high lecithin values ( 9.9 and 18.6 g./100 g.) had normal surfactant; both were born to diabetic mothers.

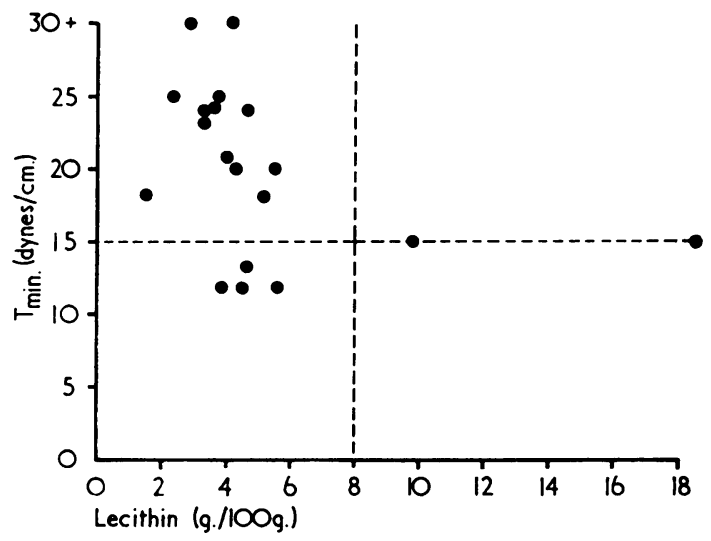

FIG. 4.-Lung lecithin related to minimum surface tension in 19 non-fresh stillbirths. The 2 cases with lecithin values in the high range were the products of diabetic pregnancy.

(d) Livebirths with hyaline membranes (Fig. 5). In this group, as in the group of livebirths without $H M$, there was a significant negative correlation between $T_{\text {min. }}$ and the lecithin content of lung. Lecithin values were consistently in the low range, with 33 of the 35 cases below $8 \mathrm{~g} . / 100 \mathrm{~g}$.

As would be anticipated, the majority of the lungs with HM (26 of 35) had abnormal surface tension $\left(T_{\min }>15\right.$ dynes $/ \mathrm{cm}$.). The remaining 9 cases had normal surface tension despite the presence of HM histologically, and these are considered in detail in the Discussion (see Table I).

Relation of minimum surface tension to gestational age. Fig. 6 gives results for $T_{\min }$. in a series of 53 perinatal deaths, composed of those cases from the present series and from that of Part I where the gestational age was known, cases with hyaline membranes and non-fresh stillbirths being excluded.

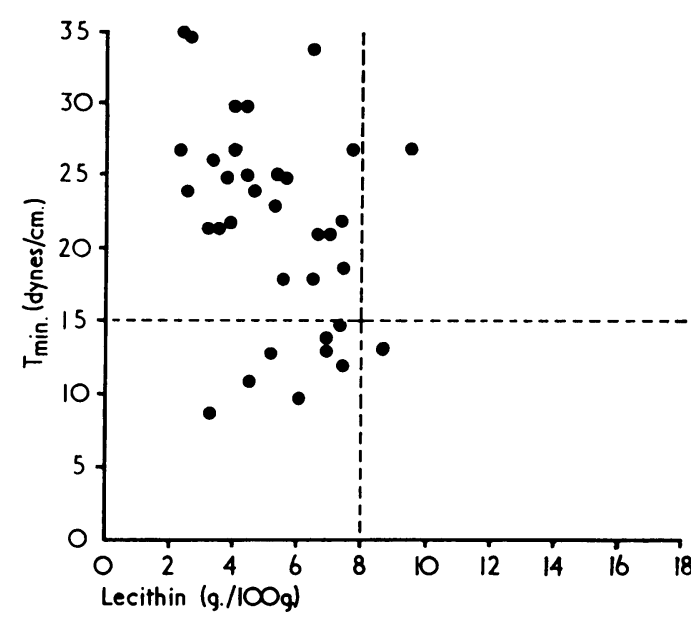

FIG. 5.-Lung lecithin related to minimum surface tension in 35 neonatal deaths with hyaline membranes. Lung lecithin is almost entirely in the low range; and surfactant is deficient in the majority, but in 9 of the 35 cases is normal $r=-0.3679 ; 0.01<p<0.05$.

$T_{\text {min. }}$ is negatively correlated with length of gestation in both stillbirths and livebirths. Of the 17 stillbirths, all 14 of 30 weeks' or more gestation had normal surfactant, while the 3 of 26 weeks' or less had abnormal surfactant.

Of the 36 livebirths, all except 7 had normal surfactant, and 5 of these 7 fell into a distinct group, both in that they were immature and because

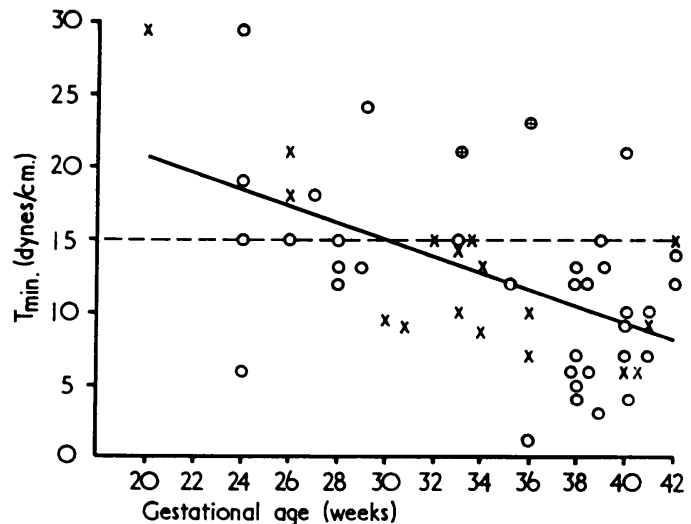

FIG. 6.-Minimum surface tension related to gestational age in 53 perinatal deaths, excluding cases with HM. 36 livebirths (O), including 2 with renal agenesis and lung hypoplasia $(\oplus) ; 17$ fresh stillbirths $(X)$. Livebirths: $r=-0.4556,0.001<p<0.01$. Stillbirths: $r=$ $-0.7515, p<0.001$. The regression line, $y=$ $31 \cdot 1680-0.5494 x$, is calculated from the combined series, for which $r=-0.5333, p<0.001$. 
TABLE I

Nine Livebirths where Pulmonary Hyaline Membrane Present with Normal Surface Tension

\begin{tabular}{|c|c|c|c|c|c|c|c|c|c|c|c|}
\hline $\begin{array}{l}\text { Case } \\
\text { No. }\end{array}$ & $\begin{array}{l}\text { Gesta- } \\
\text { tion } \\
\text { (wk.) }\end{array}$ & $\begin{array}{l}\text { Weight } \\
\text { (kg.) }\end{array}$ & Delivery & $\begin{array}{c}\text { Age } \\
\text { at } \\
\text { Death }\end{array}$ & $\begin{array}{l}\text { T min. } \\
\text { (dynes/ } \\
\text { cm.) }\end{array}$ & $\begin{array}{l}\text { Bubble } \\
\text { Click }\end{array}$ & $\begin{array}{c}\text { Bubble } \\
\text { Stabi- } \\
\text { lity } \\
\text { Ratio* }\end{array}$ & \begin{tabular}{|} 
Lecithin \\
$(\mathrm{g} \cdot /$ \\
$100 \mathrm{~g})$.
\end{tabular} & $\begin{array}{c}\text { Hyaline } \\
\text { Membrane } \\
\text { Grading } \\
(1-3)\end{array}$ & $\begin{array}{l}\text { Osmiophilic } \\
\text { Granules } \\
\text { Grading } \\
(1-3)\end{array}$ & Remarks \\
\hline 1 & 35 & 3.09 & $\begin{array}{l}\text { CS after } \\
\text { spont. rup- } \\
\text { ture of } \\
\text { membranes }\end{array}$ & $14 \mathrm{hr}$. & 11 & + & 0.46 & $4 \cdot 50$ & 3 & & $\begin{array}{l}\text { Maternal diabetes; } \\
\text { PM, biliary atresia } \\
\text { in addition to } \\
\text { HMD }\end{array}$ \\
\hline 3 & 38 & $2 \cdot 23$ & $\begin{array}{l}\text { CS after } \\
\text { spont. onset } \\
\text { labour }\end{array}$ & $80 \mathrm{hr}$. & 12 & + & 0.54 & $7 \cdot 45$ & 3 & 3 & $\begin{array}{l}\text { Maternal diabetes; } \\
\text { hydramnios; } \\
\text { IPPV }\end{array}$ \\
\hline 4 & 40 & $3 \cdot 30$ & Vertex & $48 \mathrm{hr}$. & 13 & + & 0.73 & $5 \cdot 09$ & 2 & & $\begin{array}{l}\text { Massive intra-alveolar } \\
\text { haemorrhage }\end{array}$ \\
\hline 5 & 39 & $2 \cdot 22$ & Breech & $8 \mathrm{hr}$. & 9 & + & 0.67 & $3 \cdot 28$ & 1 & & $\begin{array}{l}\text { Massive intra-alveolar } \\
\text { haemorrhage; renal } \\
\text { agenesis; tracheo- } \\
\text { oesophageal fistula }\end{array}$ \\
\hline 6 & 35 & $2 \cdot 45$ & Vertex & $48 \mathrm{hr}$. & 1 & + & 062 & $8 \cdot 70$ & 2 & 1 & $\begin{array}{l}\text { Pneumothorax, pro- } \\
\text { bably from birth; } \\
\text { pulmonary } \\
\text { haemorrhage }\end{array}$ \\
\hline 7 & 36 & $3 \cdot 11$ & $\begin{array}{l}\text { Vertex after } \\
\text { SI }\end{array}$ & $24 \mathrm{hr}$. & 10 & + & 0.42 & $6 \cdot 00$ & 2 & 2 & $\begin{array}{l}\text { Severe } \mathrm{Rh} \text { disease, } \\
\mathrm{Hb} 2 \cdot 7 \mathrm{~g} \cdot \text {; birth } \\
\text { asphyxia; exchange } \\
\text { transfusion; IPPV; } \\
\text { pneumonia }\end{array}$ \\
\hline $8 a$ & 28 & $1 \cdot 04$ & Vertex & $4 \mathrm{dy}$. & 15 & ++ & 0.72 & $7 \cdot 34$ & 1 & & $\begin{array}{l}\text { Clinically, typical } \\
\text { RDS; IPPV; pulmo- } \\
\text { nary haemorrhage }\end{array}$ \\
\hline $8 b$ & 28 & $1 \cdot 00$ & Vertex & $5 \mathrm{dy}$. & 13 & ++ & $0 \cdot 70$ & $6 \cdot 87$ & 1 & 3 & $\begin{array}{l}\text { Clinically, typical } \\
\text { RDS; IPPV; pulmo- } \\
\text { nary haemorrhage }\end{array}$ \\
\hline
\end{tabular}

CS, Caesarean section; SI, surgical induction; IPPV, intermittent positive pressure ventilation.

* Bubble stability ratio; normal 0.6 or over, 0.5 is borderline.

they lived for only 1 to $2 \frac{1}{2}$ hours. The immaturity was, in 3 cases, due to extreme prematurity $(24,26$, and 29 weeks' gestation). In the other 2 it was part of the syndrome of bilateral renal agenesis and lung hypoplasia, the lung development being histologically at a much more immature stage than appropriate to the infant's gestational age (see Part I).

Both remaining liveborn cases in whom surfactant was abnormal had evidence suggesting that some surfactant was present in the lung (Cases 2 and 6 , Table II of Part I). In one, a 24-week premature infant who died at 7 hours, bubble stability was normal, and osmiophilic granules were plentiful. In the other, a full-term infant who died at 12 hours (Case 6, Table II of Part I), osmiophilic granules were plentiful (bubble stability was not investigated).

\section{Discussion}

Relation of lecithin content of lung to surface tension of extract. Both groups of liveborn infants, those with and those without HM, showed the same pattern, with surface tension values tending to be high when lung lecithins were low (Fig. 2 and 5).

No such relation was present in the stillbirths (Fig. 3 and 4): all 15 fresh stillbirths showed normal surface tension, with a wide range of lecithin values from 3.6 to $13.6 \mathrm{~g} . / 100 \mathrm{~g}$. By contrast, 13 of the 19 non-fresh stillbirths had abnormal surface tension, and all these 13 had lecithin values in the lower range, well below $8 \mathrm{~g} . / 100 \mathrm{~g}$. Of the 6 nonfresh stillbirths with normal surface tension, 2 cases stood out on account of lecithin values in the higher range (above $8 \mathrm{~g} . / 100 \mathrm{~g}$.), and it was striking that the mothers of both were diabetic.

In the whole series of 95 cases, there was a clear relation between surfactant and lecithin content of the lung. When the lung lecithin content was $>8$ g./100 g., surfactant was normal (in 21/22 cases). Conversely, the 73 cases with lung lecithin content in the lower range $(<8 \mathrm{~g} . / 100 \mathrm{~g}$.) included virtually every case with lack of surfactant $(42 / 43)$. But this 
low lecithin group also included 31 cases with normal surfactant.

These facts would be explicable if the lecithin content of lung provided some measure of the reserve from which surfactant is formed. An infant born with relatively small amounts of lecithins in the lung would then be at risk for developing surfactant deficiency, but would only do so if additional factors were present.

Lipid fractions of lung from perinatal deaths have been analysed by others, total phospholipids by Brumley, Hodson, and Avery (1967b) and 'highly-saturated choline-containing' phospholipids by Chu et al. (1965). In both series the concentrations of these lipids were found to be abnormally low in cases dying from HMD, but their data do not allow further comparison with our lecithin findings.

Evidence from animal sources gives some support for relating lung lecithin content to surfactant reserve. Brumley et al. (1967a) measured the di-saturated lecithin in the lungs of fetal lambs. It remained low throughout the first nine-tenths of gestation; at 120-130 days, at a stage when surfactant also appeared, it started to rise steeply, until at term ( 145 days) it had reached a concentration twice as high as that found in adult animals.

Surfactant related to gestational age. Fig. 6 shows that surfactant, as measured by surface tension of lung extract, tends to increase with gestation, and that after 28 weeks deficiency of surfactant is exceptional, other than in cases with HM. Of the 3 cases shown in Fig. 6 as of over 32 weeks' gestation and having abnormal values for $\mathrm{T}_{\mathrm{min} .}, 2$ had hypoplastic lungs associated with renal agenesis.

If minimum surface tension of lung extracts is accepted as providing some measure of the amount of surfactant present, then our conclusions are similar to those of Reynolds (Reynolds and Strang, 1966; Reynolds, Roberton, and Wigglesworth, 1968), that surfactant is present in functionally significant amounts by about 30 weeks, and earlier in a varying proportion of infants.

If the lecithin content of lung be considered as providing some measure of surfactant, then the main conclusion from our findings is that there is a very wide range at all gestational ages. We were unable to show any increase in the amount of lung lecithin with gestation; this is in contrast to some findings in animals. Kikkawa, Motoyama, and Gluck (1968) found that in fetal rabbits the lecithin content of lung rose steadily from $2 \cdot 2 \%$ (of dry weight) at two-thirds gestation to $8.4 \%$ at term. In lambs, a similar rise, during gestation, of the disaturated lecithin (Brumley et al., 1967a) has been referred to above.

Taking the combined evidence from measurements of surface tension and lung lecithin, it is likely that in the human, surfactant is first detectable between 20 and 24 weeks' gestation, and that thereafter it tends to increase in amount as gestation proceeds, but with a large variability.

The situation is perhaps analogous to the maturation of glucuronyl transferase during gestation. Hyperbilirubinaemia due to deficiency of this enzyme is common among premature infants but occurs also occasionally in the full-term infant.

Effects of onset of breathing on surfactant. We have emphasized the fact that surfactant deficiency has not been encountered in fresh stillbirths of over 30 weeks' gestation. By contrast, surfactant deficiency has been a common finding in infants that have died in the neonatal period, particularly those with HMD. A reasonable inference is that the start of air breathing itself must lead to a decrease in surfactant. With the creation of a gas-liquid interface a continuous lining layer of surfactant covering the alveolar surface is formed. The first few breaths could in this way rapidly consume available surfactant; replenishment would then depend on the adequacy of surfactant reserves held in the alveolar epithelial cells, and/or on the capacity of these cells to synthesize and deliver the material.

These considerations lead us to conclude that surfactant is probably almost always present at birth, except in extreme immaturity, and that surfactant deficiency develops only after ventilation has begun. Further facts bearing on this conclusion are adduced below.

Pathogenesis of hyaline membrane disease. Avery and Mead in 1959 reported that fatal cases of HMD usually showed surfactant deficiency, and this has been confirmed many times since. Theoretically, the surfactant deficiency might be (a) the immediate cause of HMD, (b) the result of HM formation, or (c) both surfactant deficiency and HM formation might stem from a common cause. Of these, we judge possibility (a) to be the most likely, since our data are consistent with the view that surfactant deficiency precedes hyaline membrane formation.

We found (see Fig. 6) that of 36 livebirths without HM, there were only 7 with deficient surfactant, and that 5 of the 7 were very immature 
(either on account of prematurity or of lung hypoplasia) and died between 1 and $2 \frac{1}{2}$ hours. A reasonable surmise is that many of these cases would have developed HM had they survived longer. This would imply that formation of HM usually requires a period of something over $2 \frac{1}{2}$ hours' breathing, which accords well with the fact that amongst the 35 cases with HM, all had survived for at least 3 hours.

The above conclusion refers to the well-formed 'mature' membranes as seen in conventional histological sections. In Table IV of Part I, details were given of 8 cases illustrating the earliest signs of HMD, as discerned in $1 \mu$ sections. All showed surfactant deficiency, though the infants had lived only from $\frac{1}{4}$ to 2 hours. However, all were very immature, 24 to 28 weeks, so that surfactant deficiency may either have existed at birth, or have developed rapidly after the onset of breathing and as a consequence of scanty reserves.

In the earliest stages of HMD (see Part I) interstitial oedema and damage to alveolar epithelial cells are conspicuous features. The cuboidal cells are functionally impaired, to judge by the almost complete absence of osmiophilic granules. Some epithelial cells become detached from their thickened basement membrane, the oedema being a possible cause for this desquamation. The resulting gaps in the epithelium allow interstitial fluid to exude into the air spaces. Hyaline membranes are thus formed by a proteinaceous exudate with necrotic cells embedded in it.

The factor of interstitial oedema, as observed histologically, has been emphasized by several previous observers (Lauweryns, 1965; deSa, 1969). Furthermore, deSa found the water content of lungs from infants with HMD to be higher than that of controls, and that exudation of fluid reached a peak at 2-4 hours, with a slow subsequent decline.

Additional facts bearing on interstitial pulmonary oedema as a factor in the development of HMD come from experiments on newborn lambs by Strang and co-workers (Humphreys et al., 1967; Normand et al., 1968). Ventilation of the lungs at birth is normally followed by a large increase in the amounts of fluid and protein carried away from the lung via lymphatics. Little or no such increase occurred in the case of lambs that were delivered prematurely, and an excess of interstitial fluid in their lungs was shown by a gain in lung weight. Histologically, lungs from premature lambs that had been ventilated for a few hours were collapsed, with widespread hyaline membranes; and surfactant was deficient. These experiments show that interstitial oedema is a prominent feature of experimental HMD, and that reduced lymphatic drainage from the lung is one means by which the fluid is retained. Whether or not surfactant deficiency existed at birth and before the lung was ventilated in the lambs was not determined in this series of experiments, the lambs having been delivered at about the time when surfactant first appears in the fetus (around 125 days). But in an earlier paper Orzalesi et al. (1965) refer to two particularly relevant experiments, where twin premature lambs were delivered; one twin in each experiment was ventilated and developed the picture of HMD along with surfactant deficiency, while the unventilated twin fetus was found to have normal surfactant. The suggestion was made that ventilation might lead to surfactant present at birth being 'removed, utilized, or inactivated'-a mechanism similar to the one we have postulated for the infant.

We suggest that surfactant deficiency, by causing alveolar collapse, usually initiates the chain of events leading to established HMD. Alveolar collapse will have the effect of increasing fluid transfer from the pulmonary capillaries into the interstitial space, and/or inhibiting its drainage from the interstitial space via the lymphatics (see Fig. 7). In this way the interstitial space will become expanded as the residual volume of air in the lung contracts.

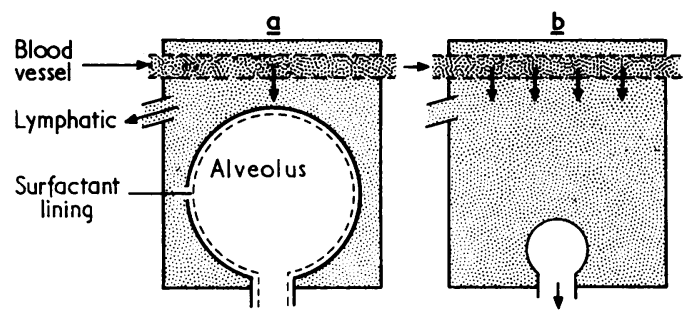

FIG. 7.-(a) Normal expanded alveolus, surrounded by small interstitial space, drained by lymphatic. (b) Alveolus, lacking surfactant lining, collapses. Its space is taken by interstitial fluid, with a fall in the flow of lymph leaving the interstitial space.

The suggested sequence of events by which the start of breathing may lead to HMD in an infant born with scanty reserves of surfactant is shown in Fig. 8. Lung aeration is pictured as leading to surfactant deficiency, and thus eventually to injury to epithelial cells. Since surfactant production is one of the functions of these cells, a vicious circle is thereby created, and this is in keeping with the course that the disease typically runs, with symptoms 


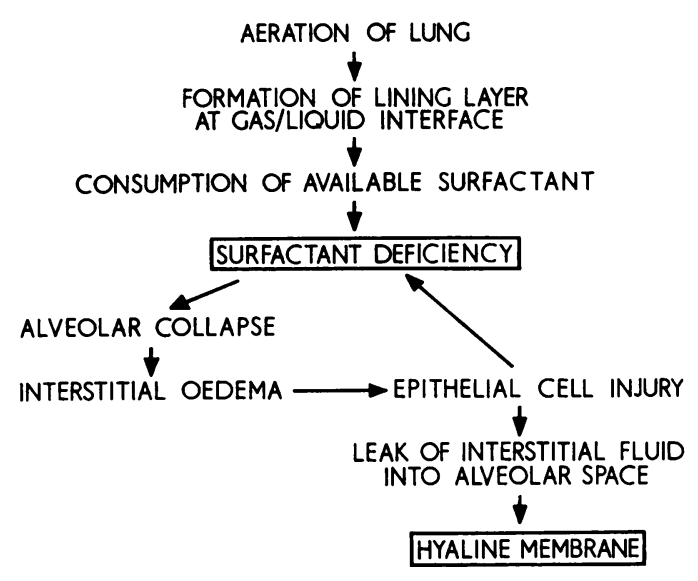

Fig. 8.-Chain of events by which the onset of breathing in an infant born with a low reserve of surfactant may cause surfactant deficiency, followed by hyaline membrane formation.

which are only mild in the first few hours after birth, but which intensify progressively over the next 1 to 2 days.

Hyaline membrane disease with normal surfactant. The scheme outlined in Fig. 8 would account for the now well-attested association between fatal HMD and surfactant deficiency, and in the present series of 35 cases with HM, surfactant was found to be deficient in 26 (Fig. 5). There remained therefore 9 cases where HM was present with normal surfactant, and consideration of these sheds some light on the relation between HM and surfactant deficiency. Details of the cases are given in Table I.

Of the 9 cases, 2 (Cases 8a, 8b; Table I) were very immature twins with a clinical picture of RDS; life was prolonged by means of IPPV to 4 and 5 days, respectively. The post-mortem appearances of the lungs were those of HMD in the repair stage, the presence of surfactant together with osmiophilic granules being characteristic of that stage (see Part I).

The remaining 7 of the 9 cases with normal surfactant were all of 35 weeks' gestation or more, and were thus relatively mature compared with the cases of HMD with surfactant deficiency, where only 6 of 26 cases were as mature as this. 3 of the cases (Cases 1, 2, and 3; Table I) form a distinct group since they were the products of diabetic pregnancy; they are discussed separately below.

Pulmonary haemorrhage was the prominent feature of Cases 4, 5, and 6. The cause of massive lung haemorrhage in the newborn is unknown, but in two cases studied under the heading "haemor- $\overrightarrow{\vec{F}}$ rhagic pulmonary oedema' by Adamson et al. $\frac{\vec{\sigma}}{\sigma}$ (1969) it was found that the bloody fluid issuing from the lung consisted essentially of a filtrate of $\bar{c}$ plasma with a low haematocrit.

In Case 7 there was gross anaemia from haemolytic disease, and the cause of death was considered $\%$ to be heart failure. (Heart failure as a cause of $\vec{\circ}$ hyaline membranes was earlier reported in a case $\vec{\overrightarrow{ }}$ of transposition of the great vessels with death on $\bar{\omega}$ the third day (Gandy et al., 1968).)

The experience of Reynolds et al. (1968) in this context was entirely comparable with ours. Among if 11 cases detailed in their 'hyaline membranes, i surfactant present' group of perinatal deaths, there $\vec{A}$ were 3 with hydrops fetalis, 2 with pulmonary $\omega$ haemorrhage, and 2 with 'resolving HMD', corresponding to our stage of repair.

We conclude that hyaline membranes may be $\rightarrow$ formed under a variety of neonatal conditions which $\subseteq$ involve extravasation of blood or oedema fluid $\vec{\nabla}$ into the lungs, and that surfactant may then $\overrightarrow{0}$ be present in lung extracts. In contrast to the 'classical' type of HMD where the membranes are widespread and conspicuous, in these cases their distribution is patchy. We have observed that osmiophilic granules are absent in areas where there are hyaline membranes, but present in other areas affected by intra-alveolar oedema or haemorrhage, suggesting that surfactant deficiency may be confined to areas with hyaline membrane.

Hyaline membrane disease in infants of diabetic mothers. We have studied the lungs of 7 infants born to diabetic mothers; details are set out in Table II. Cases 1, 2, and 3, who were all of 35 weeks' gestation or more, had the clinical signs of RDS, and lung sections had the typical appearance of HMD (HM $3+$ ). Surfactant was present in all. Osmiophilic granules were plentiful $(2+$ or $3+)$ in the 2 cases examined for these. Unlike the preceding group of cases discussed, there was no extravasation of oedema fluid or blood into the air spaces.

In seeking to interpret the combination in these cases of HMD with normal surfactant, we have considered whether relatively mature infants such as these could have passed through an earlier phase of surfactant deficiency and survived long enough to reach the repair phase, and hence to have regained surfactant. Early signs of repair were present in Cases 2 and 3 which died aged 44 hours and 80 hours, but Case 1, which died much earlier 
aged 14 hours, though not investigated by $1 \mu$ lung sections, would have been unlikely to have shown signs of repair, to judge from the fact that the earliest we have seen these is 36 hours.

The presence of surfactant in the diabetic cases also differs from our experience with other relatively mature infants that have developed HMD. We have records of 7 such infants of 35 weeks' gestation or more, additional to those included in the present series: 6 of the 7 died between 30 hours and $3 \frac{1}{2}$ days, and surfactant was deficient in all. Only in the remaining case, an infant that survived longer (with IPPV) for 7 days, was surfactant found to be normal in lungs which were histologically in the repair phase (Case 9, Table V of Part I).

Thus HMD as seen in infants of diabetic mothers seems to be of a unique kind, the presence of surfactant differentiating it from the 'classical' type of HMD.

Our data also suggest that the infants of diabetic mothers may even be exceptionally well endowed with surfactant. Thus surfactant was present in all 4 stillbirths, including the 3 that were macerated (Cases 5-7, Table II), which was an uncommon finding (see Fig. 4). Furthermore, the 2 macerated stillbirths in which lung lecithin was measured (Cases 5 and 6, Table II) had much higher values $(9.9$ and $18.6 \mathrm{~g} . / 100 \mathrm{~g}$.) than any of the other 17 non-fresh stillbirths (see Fig. 4).

The paradox of HMD occurring in infants of diabetic mothers, apparently in the presence of ample surfactant, is at present unexplained.

\section{Conclusions}

Fig. 9 represents diagrammatically a suggested scheme for the pathogenesis of HMD of the "classical' type, i.e. that which occurs predominantly in

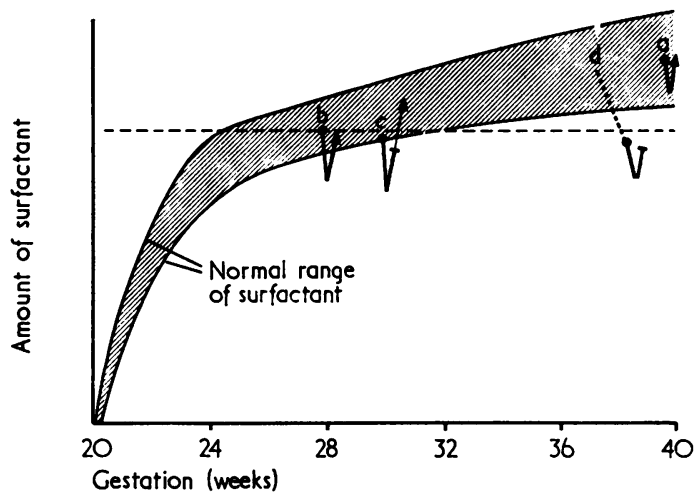

FIG. 9.-Hypothetical scheme relating amount of lung surfactant (shaded area) during gestation to development of HMD. The broken horizontal line indicates a critical level of surfactant, below which lung compliance is affected, and clinical symptoms of RDS occur. Onset of air breathing at birth (०) is represented as temporarily reducing amount of surfactant effectively available in 4 individual subjects: (a) Normal term infant; at no time does surfactant fall below critical level. (b) 28-week premature infant born with average amount of surfactant for gestational period, falling after birth only temporarily below critical level. Clinically represented by $R D S$ with recovery. (c) 30-week premature infant with belowaverage amount of surfactant at birth; consequently postnatal fall below critical level is more prolonged, leading to death. If survival prolonged by IPPV (thin line), surfactant may be replenished. (d) Near-term infant with intrauterine hypoxia resulting in impaired surfactant production before birth (broken line); consequently born with surfactant below critical level, and death.

premature infants, and is associated with surfactant deficiency. Surfactant deficiency arising in the immediate postnatal period is represented as depending largely upon a very variable amount of

TABLE II

Seven Perinatal Deaths in Infants of Diabetic Mothers

\begin{tabular}{|c|c|c|c|c|c|c|c|c|c|c|}
\hline $\begin{array}{l}\text { Case } \\
\text { No. }\end{array}$ & $\begin{array}{l}\text { Gestation } \\
\text { (wk.) }\end{array}$ & $\begin{array}{l}\text { Weight } \\
\text { (kg.) }\end{array}$ & Delivery & $\begin{array}{l}\text { Age at } \\
\text { Death }\end{array}$ & $\begin{array}{c}\mathrm{T} \text { min. } \\
\text { (dynes/cm.) }\end{array}$ & $\begin{array}{c}\text { Bubble } \\
\text { Click }\end{array}$ & $\begin{array}{c}\text { Bubble } \\
\text { Stability } \\
\text { Ratio }\end{array}$ & $\begin{array}{l}\text { Lecithin } \\
(\mathrm{g} . / 100 \mathrm{~g} .)\end{array}$ & $\begin{array}{c}\text { Hyaline } \\
\text { Membrane } \\
\text { Grading } \\
(1-3)\end{array}$ & $\begin{array}{l}\text { Osmiophilic } \\
\text { Granules } \\
\text { Grading } \\
(1-3)\end{array}$ \\
\hline $\begin{array}{l}1^{\star} \\
2^{\star} \\
3^{\star}\end{array}$ & $\begin{array}{l}35 \\
35 \\
38\end{array}$ & $\begin{array}{l}3 \cdot 09 \\
3 \cdot 35 \\
2 \cdot 23\end{array}$ & $\begin{array}{l}\text { CS } \\
\text { CS } \\
\text { CS after spont. } \\
\text { onset labour }\end{array}$ & $\begin{array}{l}14 \mathrm{hr} . \\
44 \mathrm{hr} . \\
80 \mathrm{hr} .\end{array}$ & $\begin{array}{l}11 \\
14 \\
12\end{array}$ & $\begin{array}{l}+ \\
+ \\
+\end{array}$ & $\begin{array}{l}0.46 \\
0.58 \\
0.54\end{array}$ & $\begin{array}{l}4 \cdot 50 \\
6 \cdot 90 \\
7 \cdot 45\end{array}$ & $\begin{array}{l}3 \\
3 \\
3\end{array}$ & $\begin{array}{r}- \\
2\end{array}$ \\
\hline
\end{tabular}

*Cases 1-3 in this Table also appear in Table I, where some additional data are given.

Case 7 not included in the 95 cases of the present series.

Mac. SB, macerated stillbirth; -, not examined. 
surfactant available at birth. Four clinical situations are illustrated.

(a) A normal full-term infant. (b) A premature infant with transient RDS. (c) A premature infant with severe RDS, leading to early death; or alternatively if life is prolonged by IPPV, to repair and to possible recovery (cf. Cases $8 \mathrm{a}$ and $8 \mathrm{~b}$ of Table I). (d) A mature infant, where surfactant production before birth has been impaired as a result of, for instance, fetal hypoxia, and severe RDS develops after birth. (An example of such a case, in our experience not common, is quoted in Part I.)

The scheme, in so far as surfactant is regarded as the primary defect leading to the development of HMD, is similar to that suggested by Reynolds et al. (1968). It differs from the 'hypoperfusion' theory of Chu et al. (1965), where the primary cause was thought to be pulmonary vasoconstriction, with surfactant deficiency as a consequence of this.

We thank Mr. Dennis Jones, of the School of Agriculture, University of Cambridge, for laboratory facilities, and Miss J. M. Nixon of the Department of Human Ecology, University of Cambridge, for help with statistics. K.B. and G.G. were supported by grants from the Medical Research Council, and Action for the Crippled Child.

\section{REFERENCES}

Adamson, T. M., Boyd, R. D. H., Normand, I. C. S., Reynolds, E. O. R., and Shaw, J. L. (1969). Haemorrhagic pulmonary oedema ('massive pulmonary haemorrhage') in the newborn. Lancet, 1, 494.

Avery, M. E., and Mead, J. (1959). Surface properties in relation to atelectasis and hyaline membrane disease. American Fournal of Diseases of Children, 97, 517.

Bartlett, G. R. (1951). Phosphorus assay in column chromatography. Fournal of Biological Chemistry, 234, 466.

Brown, E. S. (1962). Chemical identification of a pulmonary surface active agent (abstr.). Federation Proceedings, 21, 438.

Brumley, G. W., Chernick, V., Hodson, W. A., Normand, C., Fenner, A., and Avery, M. E. (1967a). Correlations of mechanical stability, morphology, pulmonary surfactant, and phospholipid content in the developing lamb lung. fournal of Clinical Investigation, 46, 863.

- - Hodson, W. A., and Avery, M. E. (1967b). Lung phospholipids and surface tension correlations in infants with and without hyaline membrane disease and in adults. Pediatrics, 40, 13.
Chu, J., Clements, J. A., Cotton, E., Klaus, M. H., Sweet, A. Y., Thomas, M. A., and Tooley, W. H. (1965). The pulmonary hypoperfusion syndrome. Pediatrics, 35, 733.

deSa, D. J. (1969). Pulmonary fluid content in infants with $\overrightarrow{\bar{ज}}$ respiratory distress. Fournal of Pathology, 97, 469.

Gandy, G., Bradbrooke, J. G., Naidoo, B. T., and Gairdner, D. 으 (1968). Comparison of methods for evaluating surface $\frac{\mathrm{O}}{\mathrm{O}}$ properties of lung in perinatal period. Archives of Disease in

Childhood, 43, 8.
$\longrightarrow$, Jacobson, W., and Gairdner, D. (1970). Hyaline membrane disease. I. Cellular changes. Archives of Disease in Childhood, 45, 289.

Gluck, L., Motoyama, E. K., Smits, H. L., and Kuluvich, M. V. (1967). The biochemical development of surface activity in $\overrightarrow{0}$ mammalian lung. I. The surface-active phospholipids; the separation and distribution of surface-active lecithin in the $\overrightarrow{\vec{\omega}}$ lung of the developing rabbit fetus. Pediatric Research, 1, 237. CU

Humphreys, P. W., Normand, I. C. S., Reynolds, E. O. R., and Strang, L. B. (1967). Pulmonary lymph flow and the uptake ڤิ) of liquid from the lungs of the lamb at the start of breathing. ? Fournal of Physiology, 193, 1.

Jones, D., Bowyer, D. E., Gresham, G. A., and Howard, A. N. जि (1966). An improved spray reagent for detecting lipids on $N$ thin-layer chromatograms. Fournal of Chromatography, 23, $\rightarrow$ 172.

Kikkawa, Y., Motoyama, E. K., and Gluck, L. (1968). Study of the lungs of fetal and newborn rabbits. Morphologic, biochemical, and surface physical development. American fournal of 윽 Pathology, 52, 177.

Klaus, M. H., Clements, J. A., and Havel, R. J. (1961). Composition of surface-active material isolated from beef lung. Proceedings of the National Academy of Sciences, 47, 1858.

Lauweryns, J. A. (1965). Hyaline membrane disease: a pathological study of 55 infants. Archives of Disease in Childhood, 40, 618. $\vec{\theta}$

Normand, I. C. S., Reynolds, E. O. R., Strang, L. B., and Wigglesworth, J. S. (1968). Flow and protein concentration of lymph from the lungs of lambs developing hyaline membrane disease. Archives of Disease in Childhood, 43, 334.

Orzalesi, M. M., Motoyama, E. K., Jacobson, H. N., Kikkawa, Y., Reynolds, E. O. R., and Cook, C. D. (1965). The development of the lungs of lambs. Pediatrics, 35, 373.

Reynolds, E. O. R., Roberton, N. R. C., and Wigglesworth, J. S. ำ (1968). Hyaline membrane disease, respiratory distress, and $\mathbb{D}$ surfactant deficiency. Pediatrics, 42, 758.

__ and Strang, L. B. (1966). Alveolar surface properties of the lung in the new-born. British Medical Bulletin, 22, 79.

Schlenk, H., and Gellerman, J. L. (1960). Esterification of fatty acids with diazomethane on a small scale. Analytical Chemistry, $32,1412$.

Thannhauser, S. J., Benotti, J., and Boncoddo, N. F. (1946) Isolation and properties of hydrolecithin (dipalmityl lecithin) from lung; its occurrence in the sphingomyelin fraction of animal tissues. Fournal of Biological Chemistry, 166, 669.

Usher, D. A. (1963). Estimation of phosphorus on paper chromatograms. Fournal of Chromatography, 12, 262.

Correspondence to Dr. G. Gandy, Cambridge Maternity Hospital, Mill Road, Cambridge. 